\title{
Electrocatalytic hydrogenation of phenol over Pt and Rh: unexpected temperature effects resolved
}

Nirala Singh, ${ }^{\dagger \dagger}$ Yang Song, ${ }^{\S}$ Oliver Y. Gutiérrez, ${ }^{\S}$ Donald M. Camaioni, ${ }^{\dagger}$ Charles T. Campbell, ${ }^{\ddagger}$ Johannes A. Lercher* ${ }^{\dagger}, \$$

$\dagger$ Institute for Integrated Catalysis, Pacific Northwest National Laboratory, Richland, Washington 99354, United States

\$ Department of Chemistry, University of Washington, Seattle, Washington, 98105, United States

§Department of Chemistry and Catalysis Research Institute, Technische Universtät München, Garching 85747 , Germany

* johannes.lercher@ch.tum.de

\section{Supporting Information}

\section{Experimental}

\section{Reaction Solution and Standards Preparation}

Solutions were prepared using Millipore water, phenol, acetic acid and sodium acetate. The $\mathrm{Pt} / \mathrm{C}$ and $\mathrm{Rh} / \mathrm{C}$ catalysts were from Sigma Aldrich (5 wt $\% \mathrm{Pt} / \mathrm{C}$ and $5 \mathrm{wt} \% \mathrm{Rh} / \mathrm{C}$ ). Standards for calibrating the gas chromatograph were prepared using phenol, cyclohexanol and cyclohexanone in dichloromethane with a dimethoxybenzene internal standard. All chemicals were supplied by Sigma Aldrich.

\section{Thermal Catalytic Hydrogenation Studies}

For atmospheric pressure studies a sealed glass cell with outer heating jacket was filled with 50 $\mathrm{mL}$ solution with catalyst and heated to reaction conditions. The solution was stirred at $500 \mathrm{rpm}$ to ensure suspension of the catalyst in solution and enhance mass transport. Hydrogen was continuously flowed through the reactor with an exit pressure of 1 bar during the reaction, and $1 \mathrm{~mL}$ aliquots were taken periodically using a syringe to sample the reaction progress. At $80{ }^{\circ} \mathrm{C}$, the vapor pressure of water makes a large contribution $\left(0.45\right.$ bar) to this total pressure, so the $\mathrm{H}_{2}$ pressure is only 0.55 bar there. At $60{ }^{\circ} \mathrm{C}$ the water vapor pressure is 0.2 bar so the $\mathrm{H}_{2}$ pressure is 0.8 bar. The amount of catalyst was varied to investigate the impact on the measured reaction rate. Both $50 \mathrm{mM}$ acetate buffer and water were used for testing, and the effect of acetate was determined to be minimal.

A Parr reactor was used to determine reaction kinetics at elevated pressures (2-30 bar). The reactor vessel was sealed after adding $80 \mathrm{~mL}$ of reactant solution and $10 \mathrm{mg}$ of the catalyst, and then filled with the specified pressure of hydrogen (three cycles of filling to 30 bar and venting were used to remove 
any air in the vessel prior to the final pressurization of hydrogen). The reactor was then heated to the reaction temperature under gentle stirring with an impeller, after which the impeller was set to the maximum rotation rate (approximately $660-680 \mathrm{rpm}$ ). At the conclusion of the specified reaction time the stirring was slowed, and the reactor vessel was cooled using an ice bath to $15^{\circ} \mathrm{C}$ and the gas was vented before product analysis of the liquid solution. The amount of hydrogen in the gas phase was more than 10 times the stoichiometric amount for complete conversion of phenol to cyclohexanol unless mentioned. For the 2 bar hydrogen test, because the Parr reactor had a minimum pressure reading, the reactor was filled with 2:1 nitrogen and hydrogen to 12 bar, then vented to 6 bar so that 2 bar $\mathrm{H}_{2}$ and 4 bar $\mathrm{N}_{2}$ remained. Because the 1 bar total pressure studies showed minimal effect of the acetate buffer on the thermal catalytic hydrogenation rates, the reactors at high pressure were all done in the absence of the acetate buffer.

Product Analysis

Samples were extracted using dichloromethane with an internal standard of dimethoxybenzene. Four extraction cycles were used, followed by further removal of water in the extracted sample with sodium sulfate. For samples containing acetate buffer the sample was first neutralized using sodium bicarbonate prior to extraction. Extraction was considered complete by ensuring that further extraction did not result in removal of measurable concentration of organic products from the aqueous sample. These dichloromethane samples with internal standard were run through an Agilent Technologies 5975C Gas Chromatograph with Mass Spectrometer. Peak areas were compared to calibration standards to calculate product and reactant concentrations. Conversion was calculated based on the amount of cyclohexanone and cyclohexanol. Carbon balances were above $80 \%$ except for measurements from long times in the flow reactor, where the products began to evaporate and exit in the effluent gas stream. The catalyst did not impact extraction efficiency. Turnover frequencies (TOFs) were calculated based on Pt and Rh surface area measured by hydrogen dispersion as discussed in previous work. ${ }^{1}$

\section{Electrocatalytic Reduction}


A two compartment cell with Nafion 117 proton exchange membrane (Ion Power, Inc.) was used for electrochemical tests. A carbon felt loaded with $20 \mathrm{mg} \mathrm{Rh} / \mathrm{C}$ particles was used as the working electrode in the cathode cell. A platinum wire was used as the counter electrode in the anodic compartment. A home-made $\mathrm{Ag} / \mathrm{AgCl}$ electrode was used as the reference electrode. Acetate buffer (50 $\mathrm{mM}$ ) from Sigma Aldrich was used as the electrolyte. The cell was stirred at $500 \mathrm{rpm}$. The working electrode was polarized at $-40 \mathrm{~mA}$ for 30 minutes (in the absence of phenol electrolyte) prior to ECH.

\section{Results: Thermal Catalytic Hydrogenation Rates}

Avoiding Mass Transfer Limitations in Atmospheric $\mathrm{H}_{2}$-Flow Reactor
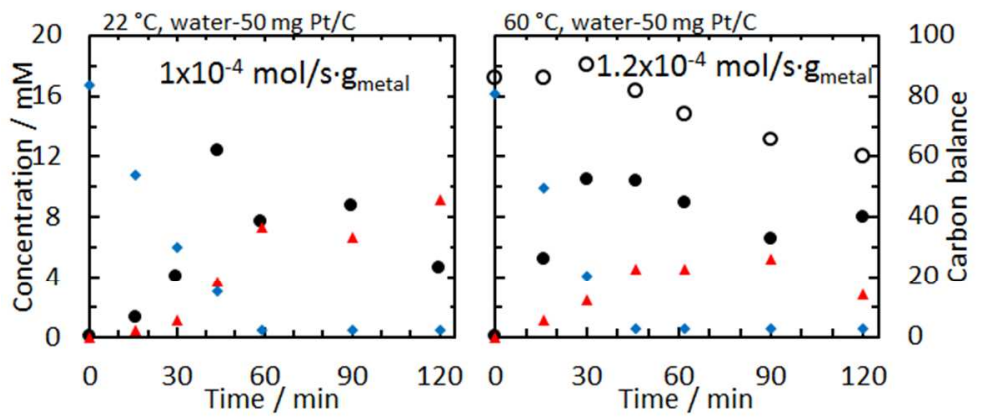

Phenol

Cyclohexanone

Cyclohexanol
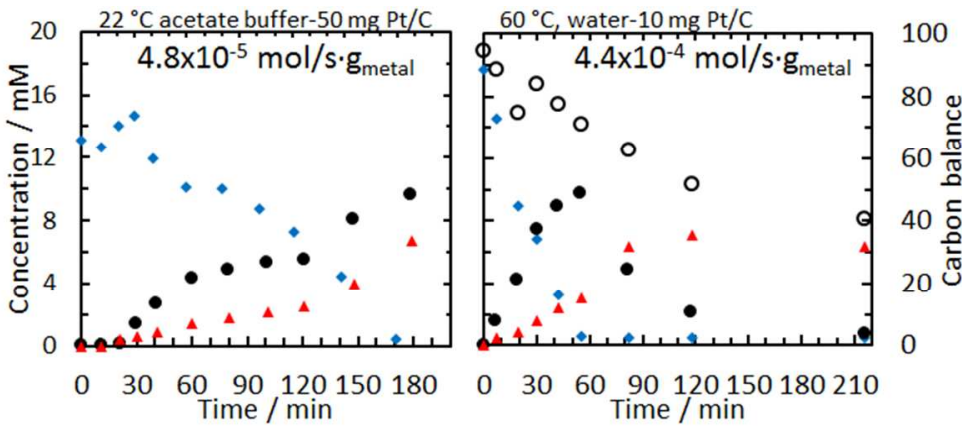

Carbon balance

Figure S1. Concentration vs. time for specified conditions in flow reactor. Acetate buffer concentration was $50 \mathrm{mM}$ for samples indicated. Phenol initial concentration was $18 \mathrm{mM}$. Stir rate was $500 \mathrm{rpm}$. Hydrogen was bubbled through the reactor at 1 bar total pressure $\left(80 \% \mathrm{H}_{2}\right.$ at $60{ }^{\circ} \mathrm{C}$, the rest being the equilibrium water vapor pressure). Initial solution volume was $50 \mathrm{~mL}$.

From the measured results in water at $60{ }^{\circ} \mathrm{C}$, there was a nearly 4 -fold increase in the rate of conversion of phenol using $10 \mathrm{mg}$ of catalyst compared to $50 \mathrm{mg}$ (Figure $\mathrm{S} 1$ ), which we attribute to mass transport limitations. At higher amounts of catalyst, suspension of the catalyst in solution became increasingly more difficult and at $50 \mathrm{mg}$ it is possible some of the catalyst remained aggregated together, inhibiting efficient mass transport to some of the catalyst. To avoid this, a lower amount of catalyst (5 
$\mathrm{mg}$ ) was used to measure reaction rates. The TOFs and reaction rates normalized to grams of catalysts were the same for $5 \mathrm{mg}$ and $10 \mathrm{mg}$ of $5 \mathrm{wt} \% \mathrm{Pt} / \mathrm{C}$ (Table S1) at the highest reaction rate conditions (60 ${ }^{\circ} \mathrm{C}$ ). This indicates that if $5 \mathrm{mg}$ of $\mathrm{Pt} / \mathrm{C}$ is used, the particles are sufficiently suspended. The changing rate with catalyst amount at high amounts, and lack of dependence on amount in the range 2 -fold above the amount used here for quantitative rate measurements $(5 \mathrm{mg})$ suggests that we have avoided mass transfer limitation (at the $500 \mathrm{rpm}$ stir rate used here, where further increase in stir speed has been shown to not affect kinetics for this system ${ }^{1}$ ). Rates were determined from initial conversions, as some of the products evaporate at higher temperatures (resulting in decreasing carbon balances as the gas-phase products were swept out by hydrogen).

Table S1. Reaction rate under different conditions in flow reactor. Stir rate was $500 \mathrm{rpm}$. Phenol initial concentration was $18 \mathrm{mM}$.

\begin{tabular}{ccccc}
\hline Solution & Temperature $\left({ }^{\circ} \mathrm{C}\right)$ & $\mathrm{H}_{2}$ pressure (bar) & Catalyst amount $(\mathrm{mg})$ & $\begin{array}{c}\text { Rate } \\
\left(\mathrm{mol} \mathrm{s}^{-1} \mathrm{~g}_{\text {metal }}^{-1}\right)\end{array}$ \\
\hline Acetate buffer & 22 & 1 & 50 & $4.8 \times 10^{-5}$ \\
Acetate buffer & 22 & 1 & 5 & $7.5 \times 10^{-5}$ \\
Water & 22 & 1 & 50 & $1 \times 10^{-4}$ \\
Water & 22 & 1 & 5 & $1.3 \times 10^{-4}$ \\
Acetate buffer & 60 & 0.8 & 5 & $4.8 \times 10^{-4}$ \\
Acetate buffer & 60 & 0.8 & 5 & $4.7 \times 10^{-4}$ \\
Water & 60 & 0.8 & 50 & $1.2 \times 10^{-4}$ \\
Water & 60 & 0.8 & 10 & $4.4 \times 10^{-4}$ \\
Water & 60 & 0.8 & 5 & $4.5 \times 10^{-4}$ \\
Acetate buffer & 80 & 0.55 & 5 & $1.3 \times 10^{-4}$ \\
Water & 80 & 0.55 & 5 & $1.1 \times 10^{-4}$ \\
\hline
\end{tabular}

Summary of Reaction Rates at 1 bar total pressure (0.55 to 1 bar $\left.\mathrm{H}_{2}\right)$

All the reactions with $50 \mathrm{mg}$ catalyst used showed lower normalized rates than reactions under the same conditions with only 10 or $5 \mathrm{mg}$ catalyst, due to mass transfer limitations, but not below $10 \mathrm{mg}$ (Table S1). Rates reported in the main text are only from the $5 \mathrm{mg}$ catalyst reactions. The rates increased from 22 to $60^{\circ} \mathrm{C}$, and were similar in acetate buffer or water (Figure S2). 

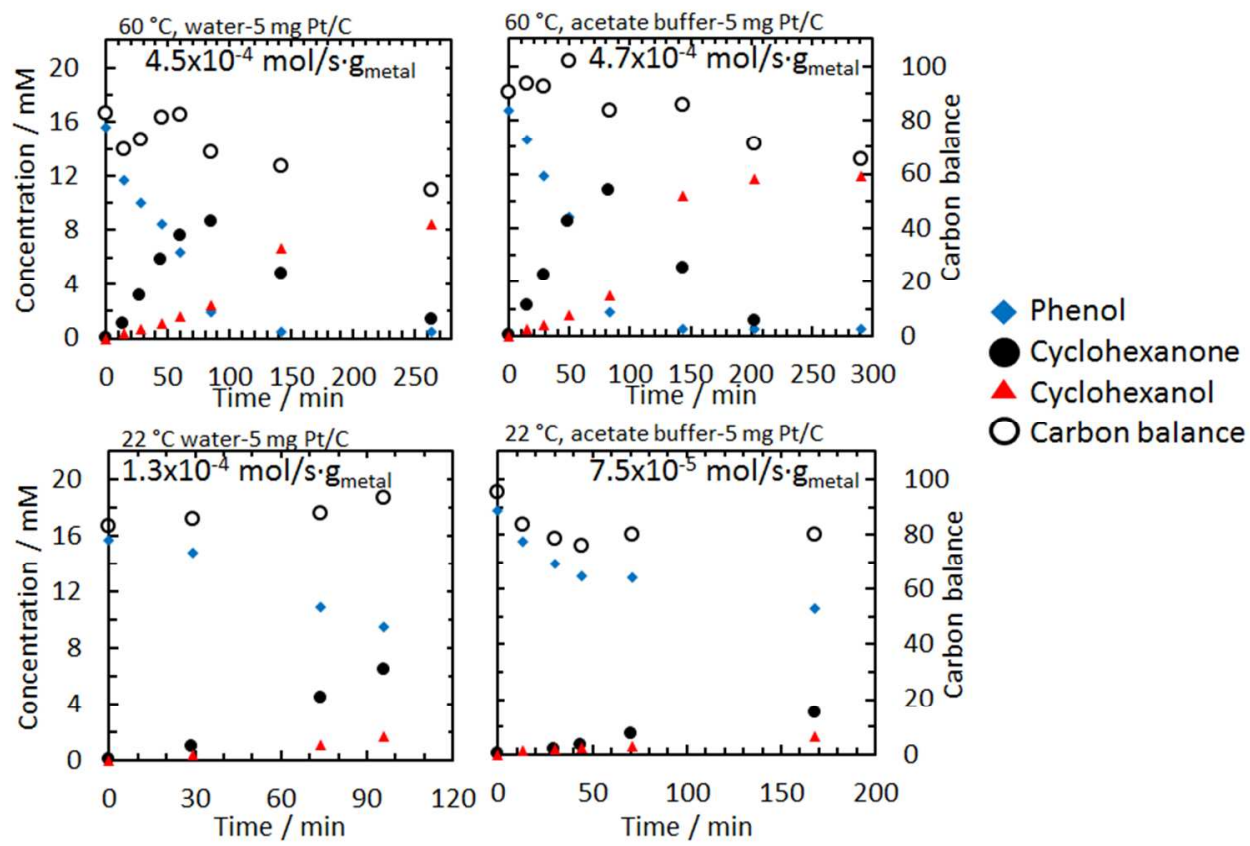

Figure S2. Concentration vs. time for $5 \mathrm{mg}$ samples in flow reactor at 1 bar total pressure. Acetate buffer concentration was $50 \mathrm{mM}$ for samples where indicated. Initial concentration was $18 \mathrm{mM}$ phenol. Stirred at $500 \mathrm{rpm}$ with 1 atmosphere hydrogen flowing. Catalyst was $5 \mathrm{wt} \% \mathrm{Pt} / \mathrm{C}$. Solution volume was $50 \mathrm{~mL}$.

At $80{ }^{\circ} \mathrm{C}$, the reaction rate decreased, possibly due to the increased vapor pressure of water, which decreases the partial pressure of hydrogen to 0.55 bar (Figure S3).
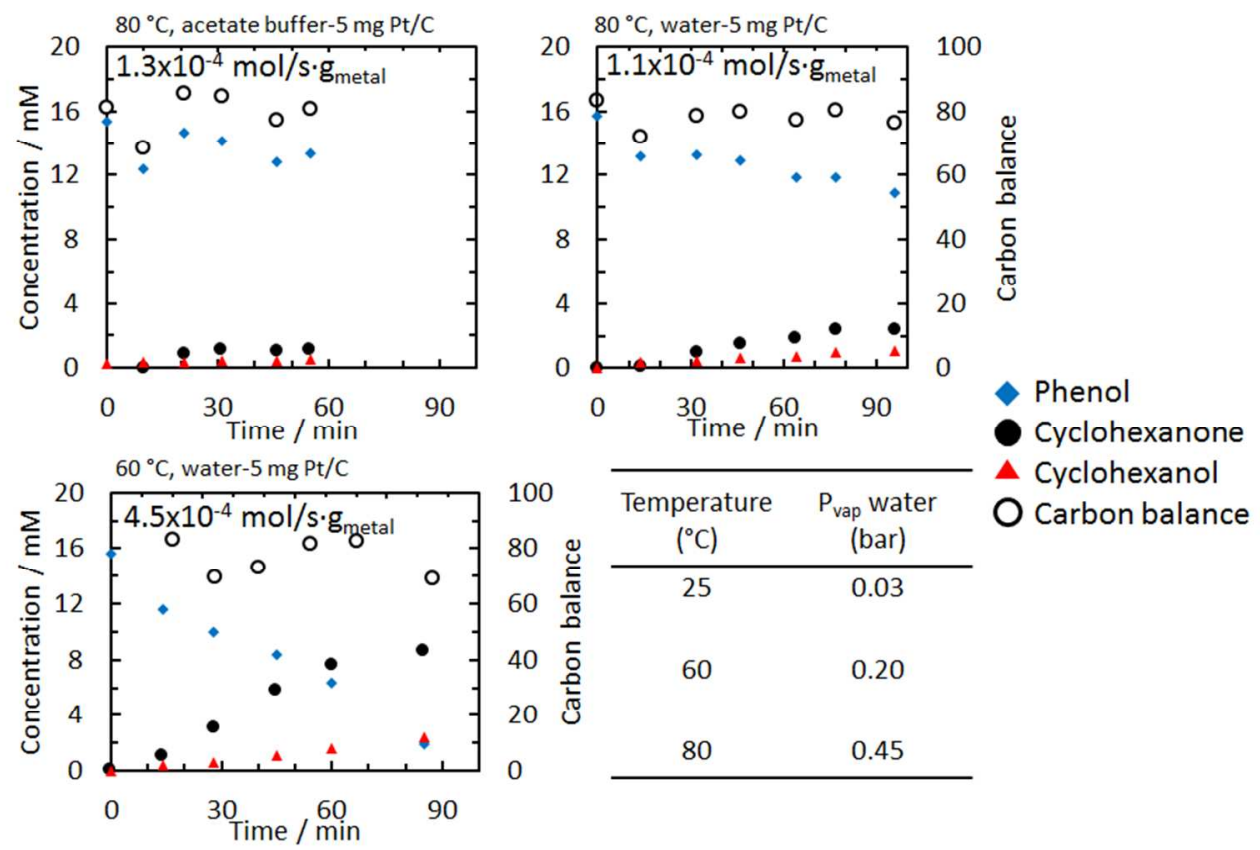

Figure S3. Concentration vs. time for $5 \mathrm{mg}$ samples in flow reactor at 1 bar total pressure. Acetate buffer concentration was $50 \mathrm{mM}$ for samples where indicated. Initial concentration was $18 \mathrm{mM}$ phenol. Stirred at $500 \mathrm{rpm}$ with 1 atmosphere hydrogen flowing. Vapor pressure of water at different temperatures is also 
listed, as it decreases the partial pressure of hydrogen during the reaction since the total pressure remains at 1 bar. Catalyst was $5 \mathrm{wt} \% \mathrm{Pt} / \mathrm{C}$. Solution volume was $50 \mathrm{~mL}$.

\section{Mass Transfer Effects in the Autoclave Reactor}

Varying the impeller speed increased the rate at low speeds but had no further effect above 400

rpm in the autoclave reactor (Figure S4). This indicates that external mass transfer was not limiting for all autoclave reactions discussed here (where the rotation rate was set to $660-680 \mathrm{rpm}$ for the rate measurements reported here) even at the highest rates of reactions measured.

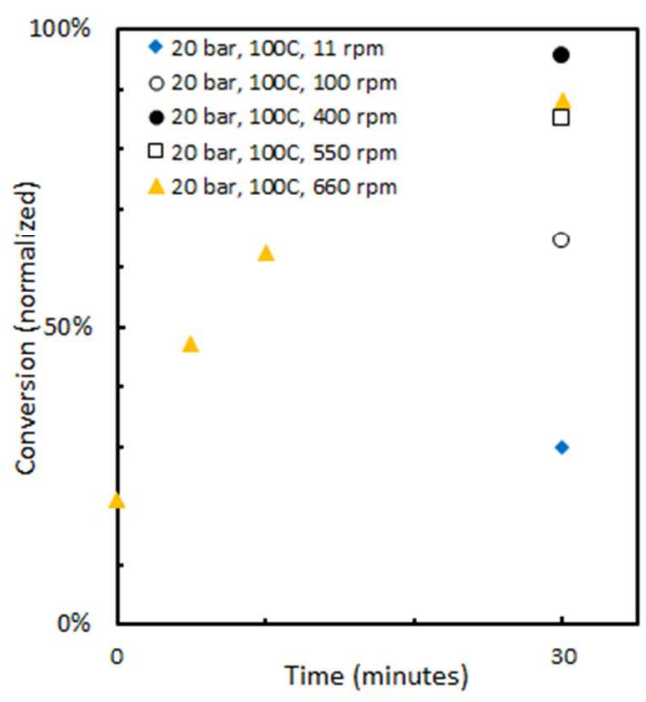

Figure S4. Phenol conversion in Parr reactor with different impeller speeds. Reaction at 20 bar hydrogen pressure, $100{ }^{\circ} \mathrm{C}$ with $10 \mathrm{mg}$ of $5 \mathrm{wt} \% \mathrm{Pt} / \mathrm{C}$ catalyst and $170 \mathrm{mM}$ phenol in water, which is a condition with the fastest TOF (see main text). 


\section{Summary of TCH Reaction Rates}

The reaction rates plotted in the figures in the Main Manuscript are included in Table S2 for reference.

Table S2. Reaction rates of phenol TCH in water. Rates measured at $\leq 1$ bar $\mathrm{H}_{2}$ were measured using a flow cell configuration with $5 \mathrm{mg} 5 \mathrm{wt} \% \mathrm{Pt} / \mathrm{C}$ with $500 \mathrm{rpm}$ stirring in $50 \mathrm{~mL}$ water, while rates measured at 2-30 bar were measured in a Parr reactor with $10 \mathrm{mg} \mathrm{5wt} \% \mathrm{Pt} / \mathrm{C}$ in $80 \mathrm{~mL}$ water with $670 \mathrm{rpm}$ stirring.

\begin{tabular}{cccc}
\hline Temperature $\left({ }^{\circ} \mathrm{C}\right)$ & $\begin{array}{c}\text { Initial phenol concentration } \\
(\mathrm{mM})\end{array}$ & $\begin{array}{c}\text { Hydrogen pressure } \\
\text { (bar) }\end{array}$ & $\begin{array}{c}\text { Reaction rate } \\
\left(\mu \mathrm{moles} \mathrm{c}_{\mathrm{cat}} \mathrm{s}^{-1}\right)\end{array}$ \\
\hline 22 & 17.7 & 1 & 130 \\
60 & 17.7 & $0.8^{*}$ & 450 \\
80 & 17.7 & $0.55^{*}$ & 110 \\
60 & 172 & 20 & 5000 \\
80 & 172 & $1.5^{* *}$ & 2300 \\
80 & 86 & 20 & 7700 \\
80 & 172 & $6-30$ & 8300 \\
80 & 690 & 20 & 8300 \\
100 & 172 & 20 & 19000 \\
\hline
\end{tabular}

* Because of the water vapor pressure of water, the partial pressure of hydrogen in the flow cell is lower than 1 atmosphere $\left(0.55\right.$ bar $\mathrm{H}_{2}$ assuming 1 bar total pressure and 0.45 bar water pressure for $\left.80^{\circ} \mathrm{C}\right)$

** Unlike the $>6$ bar Parr reactor studies, the amount of hydrogen present in the batch reactor at 2 bar is only $175 \%$ the stoichiometric amount for the maximum conversion of phenol measured (meaning the partial pressure of hydrogen is significantly reduced as the reaction proceeds), which impacts the measured reaction rate. An average pressure of 1.5 bar (as opposed to the starting pressure of 2 bar) is used for calculating the order in hydrogen.

\section{Product Distribution at Higher Conversions}

At higher conversions $(>60 \%)$, the decreased rate of $\mathrm{TCH}$ of phenol may be related to the increased concentration of the products or intermediates relative to phenol (Figure S5). At high pressures (10-30 bar, 86-172 $\mathrm{mM}$ phenol) the reaction proceeds by conversion of phenol to cyclohexanone up to a saturation concentration of cyclohexanone $(20 \mathrm{mM})$, after which the concentration of cyclohexanone remains nearly constant and the cyclohexanol concentration continuously increases (Figure S5a-c). At higher initial phenol concentrations this same trend is observed, although the concentration of cyclohexanone reached is slightly higher. This implies a steady state of cyclohexanone concentration. This is slightly different than the lower pressure, lower phenol concentration results, where the cyclohexanone concentration reaches a maximum and then converts completely to cyclohexanol (Figure S5d). The difference may be due to the differing starting concentrations of phenol, as the lower concentration of phenol $(17 \mathrm{mM})$ is not sufficient for the cyclohexanone concentration to reach $20 \mathrm{mM}$. The equilibrium conversion for phenol to cyclohexanone and cyclohexanone to cyclohexanol is nearly $100 \%$, and the concentrations here are all below the solubility limit in water. In addition, since the reactor 
is cooled following completion of the reaction, any products in the vapor phase are condensed prior to extraction and quantification. One possible cause for the decreased reactivity at high conversions in the high pressure studies is preferential adsorption of cyclohexanone/cyclohexanol on the surface. It is not expected that cyclohexanol was converted to other products as no products other than cyclohexanol and cyclohexanone were measured in the gas chromatograph, and the carbon balance was $>80 \%$ for all samples. Another possibility is that once the concentration of phenol is comparable to cyclohexanone, the cyclohexanone hydrogenation begins to compete with phenol hydrogenation. To test if cyclohexanone adsorption/hydrogenation competes with phenol to cause the lowered rates at $>60 \%$ conversion, we measured the rate of phenol $\mathrm{TCH}$ at $80{ }^{\circ} \mathrm{C}$ at $86 \mathrm{mM}$ phenol with $45 \mathrm{mM}$ cyclohexanone added. After 5 minutes (in addition to the time to heat the reactor to $80^{\circ} \mathrm{C}$ ) with $45 \mathrm{mM}$ cyclohexanone in the starting solution $\sim 6$ moles phenol $\mathrm{g}_{\mathrm{Pt}-\mathrm{cat}}{ }^{-1}$ were reacted, compared to 7.4 moles phenol $\mathrm{g}_{\mathrm{Pt} \text {-cat }}{ }^{-1}$ without added cyclohexanone as seen in Figure 3. This lower rate with added cyclohexanone is similar to the decrease in rate seen at $>60 \%$ conversion in Figures 2 and 3. This verifies our hypothesis that competitive adsorption of products, most likely cyclohexanone, cause the lowered rates at $>60 \%$ conversion. Understanding this competition between cyclohexanone and phenol will require further investigation of the rates of cyclohexanone hydrogenation and adsorption energy. 

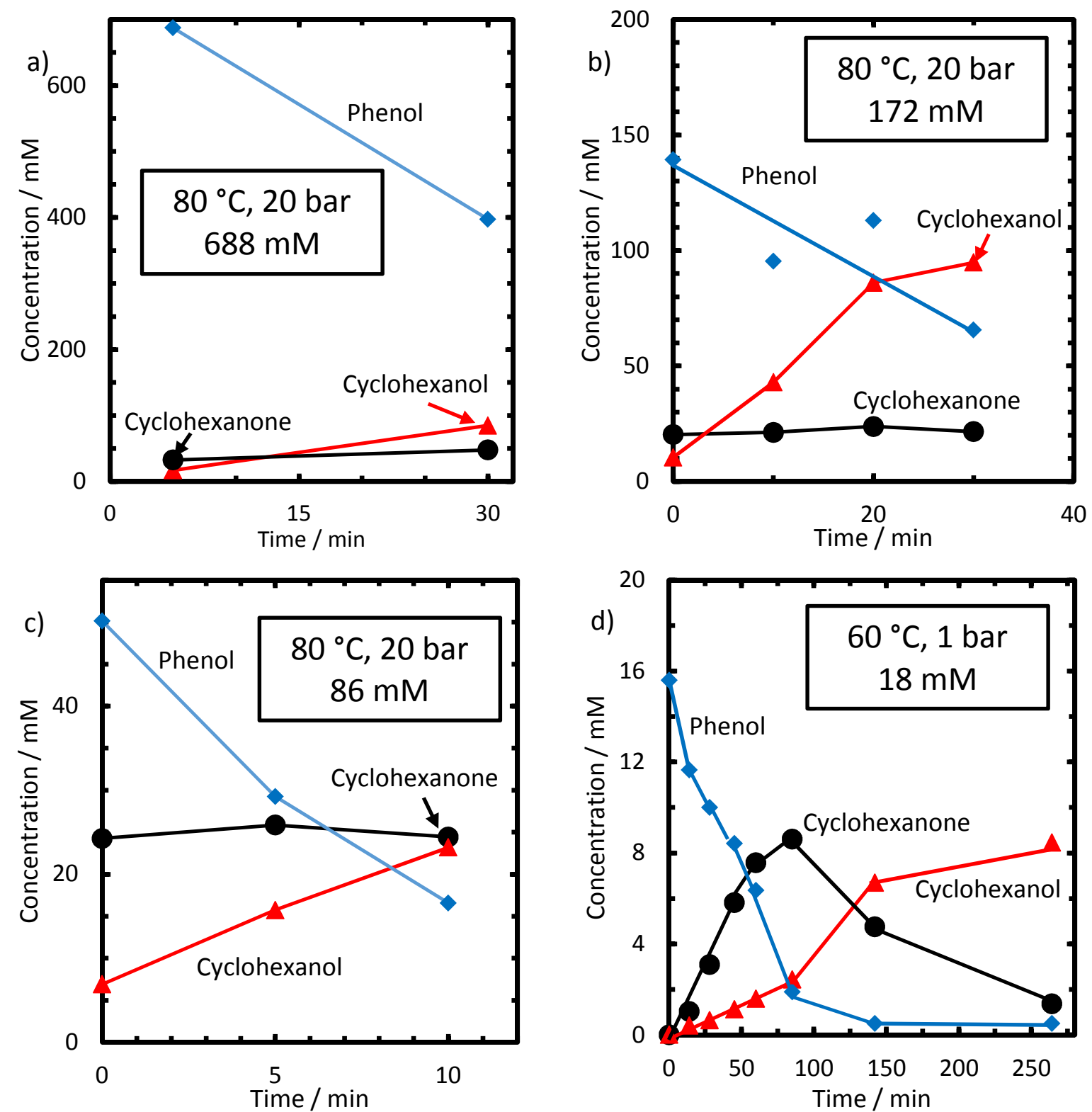

Figure S5. Thermal catalytic hydrogenation of phenol in water at 20 bar hydrogen pressure in a Parr reactor at $80{ }^{\circ} \mathrm{C}$ with starting concentration of phenol (a) $688 \mathrm{mM}$, (b) $172 \mathrm{mM}$, (c) $86 \mathrm{mM}$ in water with $10 \mathrm{mg}$ of $5 \mathrm{wt} \% \mathrm{Pt} / \mathrm{C}$ and (d) thermal catalytic hydrogenation of $18 \mathrm{mM}$ phenol in water at $60{ }^{\circ} \mathrm{C}$ and 1 bar hydrogen pressure with $5 \mathrm{mg}$ of $5 \mathrm{wt} \% \mathrm{Pt} / \mathrm{C}$. Concentrations are not normalized to amount of catalyst. Carbon balances were $>80 \%$ for (a)-(c). The carbon balance in (d) decreased with time as some amount of products evaporated and exited the reactor in the effluent gas stream. Non-zero concentrations of cyclohexanone and cyclohexanol for (a)-(c) are due to reaction during heat-up of the reactor. 


\section{Results: Electrocatalytic Hydrogenation Rates}

The ECH TOFs reported in the main text are from recent work, ${ }^{2}$ and are higher than those reported previously. ${ }^{1}$ Reference $\#^{2}$ contains a detailed explanation for the difference in rates, but in summary: the earlier TOFs ${ }^{1}$ were underestimated due to poor catalyst contact to the electrode and long ion transport distances. These issues have been corrected in reference $\#^{2}$ and the values presented in the main text come only from reference $\#^{2}$.

Maximum Rates of Thermal Catalytic Hydrogenation versus Electrocatalytic Hydrogenation

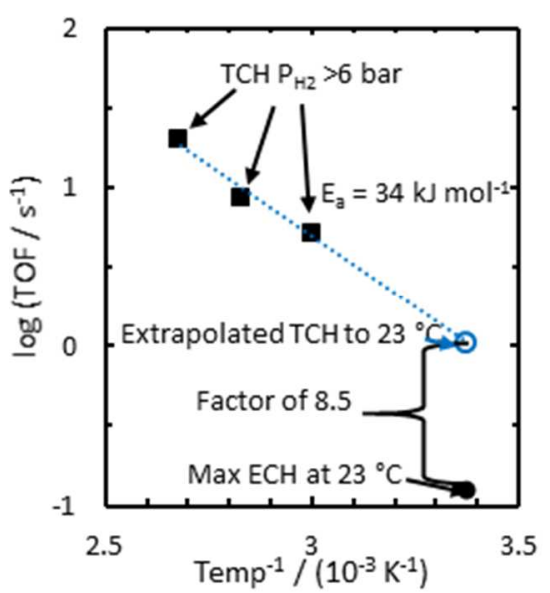

Figure S6. Arrhenius plot for maximum TCH TOFs of $\mathrm{Pt} / \mathrm{C}$ at $>6$ bar $\mathrm{H}_{2}$ pressure and extrapolated point to $23{ }^{\circ} \mathrm{C}$ based on $34 \mathrm{~kJ} \mathrm{~mol}^{-1}$ activation energy. Also shown is maximum $\mathrm{ECH}$ rate for $\mathrm{Pt} / \mathrm{C}$ at $23{ }^{\circ} \mathrm{C}$. Factor of 8.5 refers to the ratio of TOF not the ratio of $\log (\mathrm{TOF})$.

In Figure S6, the TCH TOFs at 60,80 and $100^{\circ} \mathrm{C}$ at 20 bar (the maximum TOFs were achieved at $\mathrm{H}_{2}$ pressures $>6$ bar) are shown, along with an extrapolation to $23{ }^{\circ} \mathrm{C}$ based on the activation energy of $34 \mathrm{~kJ} \mathrm{~mol}^{-1}$. This extrapolated TOF is 8.5 times larger than the maximum ECH TOF for Pt/C at $-0.35 \mathrm{~V}$ vs. RHE at $23{ }^{\circ} \mathrm{C}\left(1.0 \mathrm{~s}^{-1}\right.$ for the extrapolated TCH TOF and $0.12 \mathrm{~s}^{-1}$ for the ECH TOF). Thus, although the equilibrium $\mathrm{H}_{2}$ pressure corresponding to $-0.35 \mathrm{~V}$ vs. RHE is higher than 6 bar $\mathrm{H}_{2}$ the Nernst equilibrium (i.e., the theoretical hydrogen chemical potential is higher), the lower rate indicate that the coverage of $\mathrm{H}^{*}$ at $-0.35 \mathrm{~V}$ vs. $\mathrm{RHE}$ in $\mathrm{ECH}$ is lower than at 6 bar $\mathrm{H}_{2}$ in $\mathrm{TCH}$.

\section{Comparing Hydrogenation Turnover Frequencies to Hydrogen Electrolyzers}

The TCH TOF at $80^{\circ} \mathrm{C}$ for Pt/C measured here $\left(8.5 \mathrm{~s}^{-1}\right)$ should be achievable for ECH if a similar $\mathrm{H}^{*}$ coverage can be reached (possibly by operating at higher $\mathrm{P}_{\mathrm{H} 2}$ along with higher applied potential). 
This potentially-achievable TOF can be compared to a proton exchange membrane (PEM) $\mathrm{H}_{2}$ electrolyzer (also operated at $80^{\circ} \mathrm{C}$ ) to determine if an electrolyzer for phenol $\mathrm{ECH}$ can convert protons (or electrons) as rapidly as a PEM electrolyzer.

$$
0.05 \mathrm{mg}_{\mathrm{Pt}} \mathrm{cm}^{-2} \times \frac{1}{195} \frac{\mathrm{mol}_{\mathrm{Pt}}}{\mathrm{g}_{\mathrm{Pt}}} \times 8.5 \mathrm{~s}^{-1} \frac{\mathrm{mol}_{\text {Phenol }}}{\mathrm{mol}_{\text {surf Pt }}} \times 0.5 \frac{\mathrm{mol}_{\text {surf Pt }}}{\mathrm{mol}_{\mathrm{Pt}}} \times 4 \frac{\mathrm{mol}_{\mathrm{e}-}}{\text { mol }_{\text {Phenol }}} \times 96500 \frac{\mathrm{C}}{\text { mol }_{\mathrm{e}-}}
$$

The typical loading for the hydrogen electrode of a PEM electrolyzer is $0.05 \mathrm{mg}_{\mathrm{Pt}} \mathrm{cm}^{-2}$. Based on a 50\% dispersion ( $\sim 2 \mathrm{~nm}$ particle), and 4 electrons per phenol converted (to cyclohexanone), the current density from Equation $\mathrm{S} 1$ is $0.4 \mathrm{~A} \mathrm{~cm}^{-2}$. This is similar to the current density of a PEM electrolyzer $(0.5$ to $2 \mathrm{~A} \mathrm{~cm}^{-2}$ typically), so if the TOF of $8.5 \mathrm{~s}^{-1}$ is achieved for $\mathrm{ECH}$, an ECH electrolyzer could operate under the same current densities as a PEM $\mathrm{H}_{2}$ electrolyzer, eliminating the need for a separate $\mathrm{TCH}$ reactor. In practice, mass transport limitations may play a larger role in the operation of an $\mathrm{ECH}$ electrolyzer.

We found that the current associated with hydrogen evolution was not poisoned at $60{ }^{\circ} \mathrm{C}$ nearly as strongly as the ECH rate's poisoning shown in Figure 5, but this is expected since hydrogen evolution is so much faster that it is diffusion-limited, and therefore would be much less insensitive to poisoning.

\section{References}

(1) Song, Y.; Gutiérrez, O. Y.; Herranz, J.; Lercher, J. A. Appl. Catal. B Environ. 2016, 182, 236.

(2) Song, Y.; Chia, S. H.; Gutiérrez, O. Y.; Lercher, J. A. J. Catal. DOI: 10.1016/j.jcat.2016.09.030 